\title{
VERA DUARTE E CABO VERDE NA “ESTAÇÃO DO
}

\section{AMOR"}

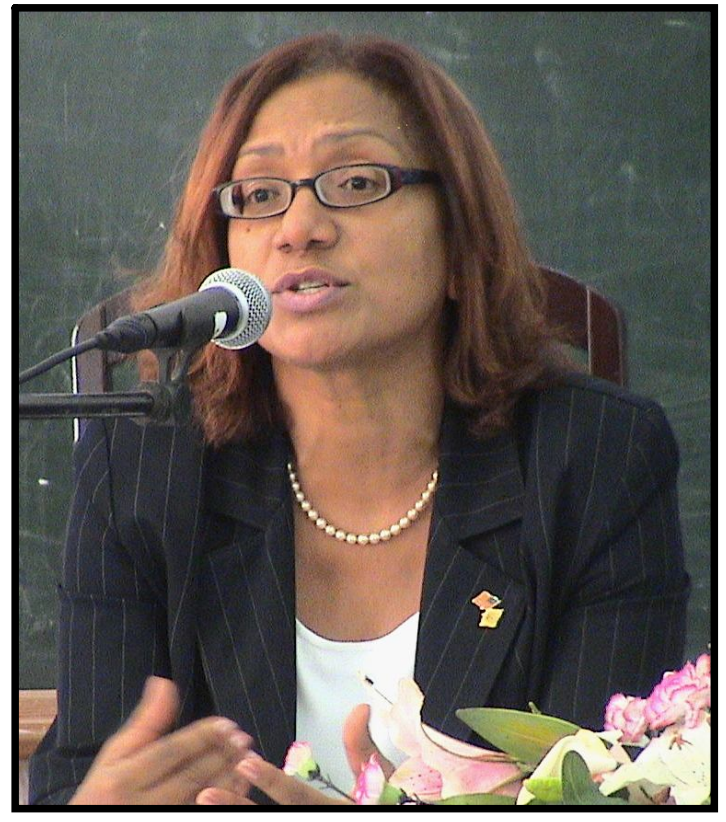

Em seu retorno a Cabo Verde, fixou-se na cidade da Praia (capital do país), Ilha de Santiago e começou sua carreira como Juiza Conselheira do Supremo Tribunal de Justiça, passando à Procuradora da República, Diretora Geral de Estudos, Legislação e Documentação do Ministério da Justiça, Conselheira do Presidente da República, Membro do Conselho Superior da Magistratura e Diretora Geral de Assuntos Judiciários do Ministério da Justiça.

Sua carreira é ainda marcada por integrar organizações nacionais e internacionais ligadas ao Direito, aos Direitos Humanos e à emancipação feminina. Atualmente é Juiza Desembargadora e Presidente da CNDCH (Comissão Nacional para os Direitos Humanos e a Cidadania) de Cabo Verde.

Na literatura, fez o seu debut em livro com a publicação da obra poética Amanhã Amadrugada (1993) Vega, Portugal. Em 2001, O Arquipélago da Paixão (poesia), publicado pela Artiletra, Cabo Verde, obtém o "Prix Tchicaya U Tam'si de Poésie Africaine" 
(poesia, 2001). Na prosa, estréia com A Candidata, União dos Escritores Angolanos, Angola, em 2003, recebendo o Prêmio Sonangol de Literatura, destinado a premiar obras inéditas de escritores de Angola, Cabo Verde e São Tomé e Príncipe. Preces e Súplicas ou os Cânticos das Desesperança, outra incursão na poesia, é publicado em 2005, sob a chancela do Instituto Piaget de Portugal. Sua obra mais recente é Construindo a Utopia, lançada em 2007.

Em reconhecimento da sua atividade profissional e cívica foi distinguida com a Medalha de Mérito Cultural pelo $30^{\circ}$. Aniversário da Independência de Cabo Verde (2005), o Prêmio Norte-Sul dos Direitos Humanos, do Centro Norte-Sul do Conselho da Europa (1995), a Distinção Máxima em Pioneirismo Feminino (1995), e foi incluida no “The World Who's Who of Woman" (1984 e 1986) e no “International Register of Profiles" (1985).

Seu nome é, hoje, sinônimo de Literatura e de Direitos Humanos em Cabo Verde.

\section{Por: Badou Koffi Robert ${ }^{1}$, Flávia Merighi Valenciano ${ }^{2}$, Genivaldo Rodrigues Sobrinho ${ }^{3}$ e Maria Alzira da Souza Santos ${ }^{4}$.}

Revista Crioula - Fale-nos um pouco da sua trajetória intelectual e da sua atuação, em várias frentes, na sociedade cabo-verdiana.

Vera Duarte - Após fazer os estudos liceais na minha terra natal S.Vicente, parti para Portugal para fazer o curso de Direito. Após a licenciatura ingressei na magistratura cabo-verdiana, tendo sido a primeira mulher a ser magistrado em Cabo Verde, na medida em que antes da proclamação da independência nacional (a 5 de Julho de 1975) tal carreira estava vedada às mulheres. Desde bastante jovem interessei-me quer pela escrita, quer pelos problemas sociais da minha terra. Em relação à escrita, comecei por escrever poesia ás escondidas 
que depois, normalmente, rasgava, dado que nessa epoca (anos 60) não se incentivava os jovens a escrever.

Só comecei a dar a conhecer a minha escrita por altura dos meus 18 anos, tendo começado a publicar em folhas soltas e suplemento literário de jornal. Com 21 anos, participei no Concurso Literário da Independencia Nacional, tendo obtido uma menção honrosa e posso dizer que foi apartir dessa altura que passei a existir enquanto protagonista literário.

Quanto as actividades de caracter social, devo dizer que seja a situação da pobreza, seja a violência contra as mulheres e, em menor escala a discriminação racial, cedo chamaram a minha atenção e comecei a desenvolver algum activismo social nesses dominios desde os meus tempos de liceu, chegando a produzir com outros colegas um programa de rádio de intervenção. A par da minha carreira profissional, tenho desenvolvido ampla actividade social e cultural, sendo membro de várias organizações ligadas aos direitos humanos, a mulher e a cultura. Em 1995 fui distinguida com o prémio Norte-Sul de direitos humanos do Conselho de Europa, fui a primeira mulher a ser eleita para a comissão africana dos direitos do homem e dos povos (1993) e sou membro do Comité Internacional de Juristas há mais de uma década. No dia 27 de Março de 2008, dia da Mulher cabo-verdiana, fui homenageada pela Organização da Mulher Cabo-verdiana pelo meu activismo em prol da mulher.

Revista Crioula - Como primeira magistrada e primeira desembargadora em Cabo Verde, resuma o papel da mulher e a sua evolução no Arquipélago.

Vera Duarte - Coincidentemente, Cabo Verde ascendeu a independência nacional no ano de 1975, ano em que teve inicio a decada das Nações Unidas para as mulheres, tendo-se realizado em 1980 a Conferência Mundial das Mulheres em Nairobi (Kénia), na qual eu participei juntamente com outras colegas. Por isso entendo que todo 
o movimento internacional inspirador da emancipação da mulher teve uma repercussão muito positiva e foi muito bem acolhido nestas ilhas. O facto de Amílcar Cabral, lider da independência nacional ter tido um pensamento extremamente progressista em relação a mulher foi também fundamental para o percurso positivo que a causa da emancipação da mulher teve em Cabo Verde. Desde as primeiras leis do novo país que se foi procurando abolir de jure todas as formas de discriminação contra as mulheres e nomeadamente a nivel de carreiras profissionais. Foi assim que tive a possibilidade de ser a primeira mulher a entrar na carreira da magistratura, em 1977, antes vedada às mulheres. Desde essa altura, a situação evoluiu muito positivamente e hoje na carreira judicial existe uma quase paridade de homens e mulheres, sendo que na carreira do ministério publico ainda existe uma clara preponderância numérica de homens face às mulheres. Eu diria que a emancipação das mulheres em Cabo Verde e o seu empoderamento cultural, social, politico e economico tem-se feito em paralelo com o desenvolvimento do nosso país.

Revista Crioula - Sabemos que há, hoje, várias mulheres produzindo literatura em Cabo Verde. Existe, nos textos literários de autoria feminina, um feminismo cabo-verdiano?

Vera Duarte - Tomando de empréstimo as palavras dos outros e nomeadamente das professoras brasileiras Simone Caputo Gomes e Carmen Lúcia Tindó Ribeiro Secco, ambas estudiosas da escrita caboverdiana, eu diria que existe neste momento uma escrita de mulheres em Cabo Verde. Acredito mesmo que um dos fenomenos maiores da literatura cabo-verdiana contemporânea é essa presença inovadora e rica da escrita feminina. Não no sentido de que ela constitua um guetto na escrita cabo-verdiana, mas sim no sentido de ela trazer para a escrita cabo-verdiana emoções e reflexões de certo modo inovadoras trazidas pela pena das mulheres que escrevem e entre as quais se pode detectar uma certa cumplicidade temática. 
Revista Crioula - E nos demais países africanos de língua oficial portuguesa, os chamados PALOP?

Vera Duarte - Do que eu tenho tido conhecimento, também me parece que já é possivel detectar algumas autoras com uma escrita própria e algo diferenciada em relação à escrita no panorama literário nos outros PALOP.

Revista Crioula - Sabemos que Vera Duarte, atualmente, é uma referência literária em Cabo Verde e uma escritora premiada. Nossos leitores gostariam muito que historiasse os principais momentos de sua trajetória literária.

Vera Duarte - Devo dizer que o primeiro momento que me marcou foi exactamente o concurso literário organizado pelo $1^{\mathrm{a}}$ aniversário da independencia nacional em que eu participei "com a cara e a coragem, como diz o meu filho mais velho" e de todos os distuinguidos eu fui a única mulher. Devido a esse concurso vim a receber uma bonita carta do escritor angolano Luandino Vieira, de quem depois me tornei grande amiga, em que ele me felicitava pelos poemas com que eu tinha participado no concurso e me incentivava a escrever. Também os escritores cabo-verdianos Luís Romano e Arnaldo França repararam em mim e incentivaram-me activamente a continuar a escrever. No desenrrolar da minha vida literária esses três escritores tornaram-se-me figuras totelares do ponto de vista literário. Depois ganhei em 1981 o primeiro lugar no concurso nacional de poesia realizado pela Organização das Mulheres de Cabo Verde, o que me deu muita alegria. Depois, em 1993 muito por influencia de Arnaldo França, publiquei o meu primeiro livro de poemas "Amanhãamadrugada" e esse foi sem dúvida um momento único. Em 2001 obtive o prémio Tchicaya U’ Tamsi da poesia africana que me foi entregue numa cerimónia lindissima em Assilah nos Marrocos que me fo i entregue por Mohamed Benaissá. Este 
prémio que anteriormente já tinha sido ganho entre outros por René Depestres e Eduard Maunick permitiu-me encetar uma convivencia muito boa com estes escritores de excepcão. Também em 2003 tive a enorme alegria de ter sido contemplada com o prémio Sonangol de literatura pelo meu livro de estreia na ficção, "A Candidata", que também me foi entregue numa cerimónia de grande beleza. Finalmente, em 2005, por ocasião das comemmorações do trigéssimo aniversário da independencia nacional, fui galardoada com a medalha de mérito cultural do governo de Cabo Verde, o que foi muito emocionante e honrroso.

Aqui e ali tenho sido privilegiada com diplomas de mérito cultural que muito me encanta, mas não cabe enumerar.

Revista Crioula - Quais os temas fundamentais desenvolvidos em seus livros publicados?

Vera Duarte - De acordo com as pessoas que tem dado atenção a minha escrita e também um pouco de acordo com aquilo que eu sinto, eu acho que a minha escrita tem navegado sobretudo por temas sociais, mas sempre com forte pendor introspectivo e emocional. Eu até diria que é sobretudo uma escrita de emoções. É evidente que em alguns dos meus livros o lirismo é também predominante. O amor intimista ocupa um espaço substancial na minha escrita, à par de um amor mais altruista, solidário e ecuménico.

Revista Crioula - Conte-nos um pouco da sua experiência como Presidente da Comissão de Direitos Humanos.

Vera Duarte - A Comissão Nacional para os Direitos Humanos e Cidadania tem-me permitido desenvolver um trabalho na minha area de eleição que são os direitos humanos. Desde a educação para os direitos humanos e cidadania, promoção da familia, da saúde e da justiça e luta contra a pobreza, com atenção especifica as crianças, mulheres, 
portadores de deficiencia, presos e imigrantes, todos são áreas em que intervem a CNDHC e são por isso áreas a que venho dando uma atenção especifica, produzindo alguma reflexão escrita e oral e realizando alguma actividade.

Revista Crioula - A senhora participou recentemente do III Encontro de Professores de Literaturas Africanas no Rio de Janeiro, com enorme sucesso. Como a senhora encara os estudos sobre as literaturas africanas de língua portuguesa e, em especial, a cabo-verdiana desenvolvidos no Brasil?

Vera Duarte - Acho que o terceiro encontro foi riquíssimo e muito bem organizado. Tivemos todos a oportunidade de realizar um diálogo importante entre as vozes literárias que formam a comunidade dos países de língua portuguesa. Sobretudo a mesa de mulheres a que se refere foi muito rica e poderosa, a evidenciar a presença de mulheres que querem fazer o seu destino. Entendo que a divulgação que o meio academico brasileiro, sobretudo universidades como a UFRJ, a UFF, a USP e a UFMG, vem fazendo das literaturas africanas em língua portuguesa tem sido absolutamente fundamental para o conhecimento extrafronteiras dessa mesma literatura e para o seu próprio processo de crescimento. A lei federal $n^{\circ} 10639 / 03$ do presidente Lula Da Silva tem sido de extrema importância nesse processo.

Revista Crioula - A senhora afirma no texto "O Atlântico, estrada cultural e a poesia cabo-verdiana do século XX" que as relações entre as culturas crioula e a brasileira compõem o que chama de "estação do amor", que sucede a "estação da dor". Explique-nos esta sua visão da história cultural crioula.

Vera Duarte - Há alguns anos tive uma intuição que achei extremamente interessante e desde então tenho procurado aprofundar alguma reflexão a propósito. Entendo que a relação nomeadamente 
entre o Brasil e Cabo Verde que agora se vem aprofundando cada vez mais é uma relação que já teve várias estações. A primeira estação a que chamo "estação da dor" deu-se quando o modelo societário que se desenvolveu nestas ilhas foi levado para o Brasil, sobretudo o nordeste, através do tráfico de escravos que eram comprados na costa ocidental africana, passavam por Cabo Verde onde eram ladinizados e daqui eram transportados para o Brasil onde iam servir nas casas grandes, levando consigo apports culturais para a sociedade brasileira. Nessa epoca, também foram animais (cabras) e plantas (cana do açucar) que modelaram indelevelmente a cultura brasileira. Posteriormente, foi a vez da cultura brasileira influenciar a cultura cabo-verdiana por mor do impacto que obras dos seus autores maiores (Castro Alves, Rui Barbosa, Olavo Bilac e depois Manuel Bandeira, José Lins do Rêgo, Guimarães Rosa, Jorge Amado) exerceram sobre autores cabo-verdianos (João Lopes, Jorge Barbosa, Baltazar Lopes). Chamo a essa a "estação da assimilação". Entendo que contemporâneamente estamos a viver uma relação de igualdade entre as duas margens do Atlântico, relação feita de diálogo, inter-influenciação e estudo, e por isso mesmo chamo a essa a "estação do amor", por ela se basear na igualdade das partes. O que eu acho interessante falando de Brasil e Cabo Verde é o facto de sendo o Brasil tão grande e Cabo Verde tão pequeno, ter havido alguma influenciação do modelo societal brasileiro pelo modelo societal caboverdiano, a ponto de, à afirmação "Cabo verde é um Brasilinho”, haver brasileiros (embaixador Victor Gobato) que afirmam perentoriamente que o Brasil é que é um grande Cabo Verde.

\footnotetext{
1 Mestrando em Estudos Comparados de Literaturas de Língua Portuguesa. Universidade de são Paulo (USP). Pesquisa: A consciência da subalternidade: trajetória
} 
da personagem porta-voz em Niketche de Paulina Chiziane. Email: marfinense2007@yahoo.com.br

2 Mestranda em Estudos Comparados de Literaturas de Língua Portuguesa. Universidade de são Paulo (USP). Pesquisa: Travessias solitárias: um estudo sobre as personagens de João Antônio e Caio Fernando Abreu. E-mail: flaviamerighi@usp.br

3 Doutorando em Estudos Comparados de Literaturas de Língua Portuguesa. Universidade de são Paulo (USP). Pesquisa: Interfaces de Eugénio Tavares no Exílio. Email: genivaldor@hotmail.com

4 Doutoranda em Estudos Comparados de Literaturas de Língua Portuguesa. Universidade de são Paulo (USP). Título da Pesquisa: A geração da utopia e Vidas Secas: ciclos de luta e resistência, caminhos de desalienação. Email: malziras@hotmail.com 